\title{
Dvolver Movie Maker: uma experiência pedagógica interativa de estudantes com deficiência intelectual
}

\author{
Ana Cláudia Pavão Siluk - UFSM - anaclaudiaoliveirapavao@gmail.com \\ Karolina Waechter Simon - UFSM - karolinasimon@gmail.com \\ Liziane Forner Bastos - UFSM - liza_fb@hotmail.com
}

\section{Resumo}

Este artigo apresenta a experiência de aprendizagem e interação aplicada a um grupo de estudantes com necessidades especiais de duas Instituições educacionais na região de Santa Maria, RS. Utilizando a ferramenta online de criação de vídeos animados Dvolver Movie Maker, e estabelecendo a interação entre as escolas por meio da criação de uma narrativa contínua e participativa, o objetivo principal deste estudo foi promover o desenvolvimento da leitura e escrita por meio da tecnologia e interação. Alguns dos objetivos específicos contemplados foram analisar e promover a interação entre os participantes; possibilitar o uso das tecnologias como recurso de ensino aprendizagem; instigar a criatividade, autoestima e a capacidade de produzir trabalho de autoria própria.

Palavras-chave: sala de recursos multifuncionais; educação especial; software educacional; dvolver movie maker

\section{Dvolver Movie Maker: an interactive experience on a multifunctional resource classroom}

\begin{abstract}
This paper presents the experience of learning and interaction applied to a group of students with special of two municipal schools in the region of Santa Maria, RS. Using the online tool for creating animated videos named Dvolver Movie Maker and establishing the interaction between schools through the creation of a continuous and participatory narrative, the main objective of this study was to promote the development of reading and writing through technology and interaction. Some of the specific objectives contemplated were to analyze and promote the interaction between the participants; Enable the use of technologies as a teaching learning resource; Instigate creativity, selfesteem and the ability to produce self-made work.
\end{abstract}

Keywords: multifunctional resource classroom; special education; educational software; dvolver movie maker

\section{Introdução}

O princípio da inclusão vem se instaurando mundialmente há algumas décadas, mas este movimento ganhou força a partir da década de 90 com a realização de algumas conferências mundiais e principalmente com a publicação da Declaração de Salamanca, a qual foi promulgada na Espanha em 1994. Este documento, que é um marco no movimento da inclusão social, tem o objetivo de estabelecer diretrizes básicas para a criação e reformulação de políticas e sistemas educacionais nos diversos países membros 
da ONU (BRASIL, 1994).

No Brasil, percebeu-se o fortalecimento das políticas e práticas de inclusão escolar, impulsionadas principalmente pela Política Nacional de Educação Especial na Perspectiva da Educação Inclusiva (PNEEPEI). Esta política tem como objetivo o acesso, a participação e a aprendizagem dos alunos com deficiência, transtornos globais do desenvolvimento e altas habilidades/superdotação nas escolas regulares, orientando os sistemas de ensino para promover respostas às necessidades educacionais especiais (BRASIL, 2008, p.14).

Além desses progressos que se refere à educação de pessoas com deficiência, também vem ocorrendo avanços no uso das tecnologias como meio de aprendizagem significativa e como facilitador de acesso aos conhecimentos. O uso de softwares educacionais é uma das formas com as quais as tecnologias têm chegado na sala de aula.

Os novos ambientes de interação, possibilitados pelas tecnologias, surgem como fatores que estruturam diferentes alternativas e concepções pedagógicas. Conforme Moran (2000, p11):

\footnotetext{
Muitas formas de ensinar hoje não se justificam mais. Perdemos tempo demais, aprendemos muito pouco, desmotivamo-nos continuamente. Tanto professores como alunos temos a clara sensação de que muitas aulas convencionais estão ultrapassadas. Mas por onde mudar? Como ensinar e aprender em uma sociedade mais interconectada?
}

No contexto da educação escolar, os novos ambientes de interação, possibilitados pelas tecnologias, surgem como fatores que estruturam diferentes alternativas e concepções pedagógicas. Desse modo, tornam-se indispensáveis no papel social da escola para a construção de uma sociedade mais inclusiva, potencializando os alunos ao desenvolvimento de uma aprendizagem autônoma, cada um à sua maneira de acordo com suas especificidades.

A partir dessas reflexões, este artigo relata a experiência da utilização de um software livre para criação de animações em vídeo com estudantes que possuem deficiência intelectual, frequentadores do Atendimento Educacional Especializado de duas escolas de municípios da região de Santa Maria, RS. A ação proposta, teve como objetivo o desenvolvimento das habilidades de leitura e escrita, bem como a promoção da interação entre os sujeitos das diferentes escolas, ao estimular a criação coletiva da narrativa em vídeo.

Ao abordar neste estudo a temática das tecnologias educacionais, pretende-se compreender a sua função enquanto recurso de inclusão e aprendizagem lúdica. Dessa forma, sugere-se que as TICs se apresentem como promissoras na implementação e consolidação de um sistema educacional inclusivo.

\section{Educação Especial}

A Educação Especial, segundo a Lei no 9394/96, é uma modalidade de ensino que perpassa todos os níveis, etapas e modalidades. Segundo Silva (2010) além de ser uma modalidade, é também uma área do conhecimento. O objetivo desta modalidade consiste no desenvolvimento de práticas e estratégias pedagógicas voltadas para alunos com necessidades educacionais especiais. 
Considera-se público alvo desta modalidade de ensino os sujeitos com deficiência, transtornos globais do desenvolvimento e altas habilidades/superdotação. A modalidade é estruturada por meio do atendimento educacional especializado - AEE. O público alvo desta modalidade deve estar matriculado nas escolas comuns do ensino regular e concomitantemente frequentar ao atendimento educacional especializado. O AEE é realizado na Sala de Recursos Multifuncionais da própria escola ou na escola mais próxima de ensino regular, preferencialmente no turno inverso da escolarização.

Neste contexto, o AEE- Atendimento Educacional Especializado é assim definido:

$\mathrm{O}$ atendimento educacional especializado tem como função identificar, elaborar e organizar recursos pedagógicos e de acessibilidade que eliminem as barreiras para a plena participação dos alunos, considerando suas necessidades específicas. As atividades desenvolvidas no atendimento educacional especializado diferenciam-se daquelas realizadas na sala de aula comum, não sendo substitutivas à escolarização. Esse atendimento complementa e/ou suplementa a formação dos alunos com vistas à autonomia e independência na escola e fora dela (MEC/SEESP, 2008, p.15).

Conforme as Diretrizes para a Educação Especial na Educação Básica (2001), o AEE tem como função identificar, elaborar e organizar recursos pedagógicos e de acessibilidade que eliminem as barreiras para a plena participação dos alunos, considerando suas necessidades específicas. Portanto, esse atendimento complementa e/ou suplementa a formação dos alunos com vistas à autonomia e independência na escola e fora dela.

\title{
3. Leitura e Escrita
}

Estudos realizados por Emília Ferreiro e Ana Teberosky (1986), demonstraram as maneiras que a criança se apropria da linguagem escrita, agindo ativamente sobre o objeto do conhecimento e construindo diferentes hipóteses ao longo de sua evolução na língua escrita.

De acordo, com Ferreiro e Ana Teberosky (1991 apud MEC/SEESP, 2007, p. 45):

\begin{abstract}
Os processos de evolução da leitura e escrita nas crianças ocorrem por meio da sua interação com a língua escrita, onde ela levanta hipóteses sobre a escrita. No qual, a leitura é um processo dinâmico que vai além da simples decodificação do código escrito, mas quando a criança compreende sobre aquilo que lê, o sentido de um texto, os conflitos são constantes e provocam mudanças significativas para a formação do leitor.
\end{abstract}

Diante disso, é possível perceber que o ato de ler vai além da simples codificação e decodificação do código escrito é a capacidade que a criança utiliza para compreender o sentido de um texto e realizar inferências sobre o mesmo.

Este viés interacionista prioriza a aprendizagem da leitura e escrita como resultado da busca de significados de um texto em situações de uso real, no qual a criança interage com os diferentes gêneros textuais e constrói significados sobre aquilo que lê.

Partindo das premissas anteriores, destacamos a importância da mediação do professor nos processos de construção da leitura e escrita pela criança, no sentido de 
estimular conflitos e desafios cognitivos utilizando recursos textuais que façam parte do contexto do aluno, que despertem o seu interesse pela língua escrita.

No que se refere, a alunos com deficiência intelectual seus processos de aprendizagem da leitura e escrita são semelhantes aos daqueles sem deficiência sob muitos aspectos, pois estes transcorrem pelos mesmos níveis de alfabetização e constroem hipóteses acerca do objeto escrito. No entanto, os alunos com deficiência intelectual, apresentam um ritmo mais lento na evolução destes níveis e necessitam da intervenção de um par mais experiente neste processo de apropriação. (MEC/SEESP, 2007)

Nessa perspectiva, segundo o MEC/SEESP (2007), ao trabalharmos com a alfabetização com estes sujeitos, é necessário exercitar a capacidade cognitiva do indivíduo propondo atividades, nas quais ele tenha uma participação ativa na realização ou que façam parte de seu cotidiano.

Dessa forma, deve-se possibilitar que os alunos possam construir a sua inteligência dentro de suas especificidades intelectuais e tornando-se agente capaz na produção de significados.

\section{Metodologia}

A pesquisa foi desenvolvida sob uma abordagem qualitativa, com ênfase nas práticas de pesquisa-ação. De acordo com Tripp (2005), na pesquisa-ação prática, o pesquisador escolhe ou projeta as ações que serão realizadas. O processo inicia quando este reflete sobre uma prática rotineira, e identifica o que se quer melhorar. O modo como o pesquisador alcançará os resultados fica por conta de suas experiências e ideias; mas também "porque o tipo de decisões que ele toma sobre o quê, como e quando fazer são informadas pelas concepções profissionais que têm sobre o que será melhor para seu grupo."

O ciclo da pesquisa se dá pela reflexão, planejamento, aplicação e análise reflexiva, que permite a adaptação e reavaliação constante de acordo com os resultados que vão surgindo. Nesse processo, pesquisadores e participantes estão envolvidos de modo cooperativo. Conforme expõe Thiollent e Oliveira (2016, p.359):

\footnotetext{
Na pesquisa-ação existe ênfase na ação. As ações são discutidas, analisadas, deliberadas, decididas com pleno consenso ou não. São ações significativas para os atores em situação, com suas próprias formas de expressão e linguagens. São interpretadas pelos pesquisadores com base em diferentes referenciais. Além disso, são ações portadoras de aprendizagem e de conhecimento mútuo, com interações entre observadores e observados.
}

Para realização desta experiência, como sujeitos, foram selecionados seis estudantes que possuem deficiência intelectual que frequentam o Atendimento Educacional Especializado nas Instituições antepostas.

Segundo o Manual diagnóstico e estatístico de transtornos mentais DSM-5 (2014), caracterizam-se por ter limitações nas habilidades mentais gerais, dificuldade no funcionamento adaptativo em comparação com indivíduos pareados por idade, gênero e condição sócio cultural e início no período de desenvolvimento, antes dos dezoito anos.

O instrumento para a coleta dos dados foi a observação e registro posterior para 
análise em diário de campo. Os acompanhamentos ocorreram individualmente, ou seja, para cada sujeito participante foram realizados os registros das observações.

O desenvolvimento da pesquisa se deu em quatro etapas. A primeira etapa consistiu na seleção dos estudantes para participar da atividade. Esta seleção se deu a partir do plano de desenvolvimento individual que já vem sendo trabalhado com o estudante (objetivos, metodologias, etc) no AEE. Diante deste, foram selecionados os alunos em que a proposta pedagógica abordava a alfabetização e que fizessem parte do público estipulado (deficiência intelectual).

A segunda etapa, consistiu na abordagem com os estudantes sobre as características das histórias em quadrinhos. Para isso, foram utilizados alguns exemplos impressos e digitais. Nessa etapa, também foi apresentado o Software Dvolver Movie Maker, com as exposições necessárias para que na próxima etapa fosse iniciada a construção da animação.

Nesta última etapa, iniciou-se o processo em que os alunos do Atendimentos Educacional Especializado de Itaara (Escola A) e São Pedro do Sul (B) realizaram a construção das animações e as trocas interativas. A1 e B1 iniciaram as animações e enviaram para B2 e A2 respectivamente. Após estes darem continuidade na animação recebida enviaram para A3 e B3 finalizarem a animação. Concomitante foi realizada a análise, que consiste na observação, coleta, registro dos dados da pesquisa e após a análise destes dados coletados.

A escolha do Dvolver Movie Maker se justifica, pois é um aplicativo online de acesso gratuito que permite, em poucos passos, a criação e compartilhamento de curtos vídeos de animações. O processo se dá em algumas etapas pré-definidas emparelhando cenários e personagens com as ideias e o texto dos usuários.

Inicia-se com a escolha do cenário (background), nesta etapa basta escolher o fundo desejado (montanha, apartamento, campo, etc) e céu (ensolarado, nevado, chovendo rosas, etc) para definir o humor para o filme. Posteriormente se define a quantidade e quais dos personagens serão definidos. Dando continuidade é feita a construção dos diálogos; seleção de trilha sonora e edição dos créditos. Após a finalização, a animação é publicada online e pode ser compartilhada não somente por email, mas também cada filme tem seu próprio URL e os filmes podem ser incorporados em outro lugar, copiando e colando o código html fornecido no próprio site do aplicativo ${ }^{1}$.

Quanto à análise dos dados, para a descrição dos resultados, foi realizada a análise de conteúdo, que na percepção de Bardin (2011), consiste numa técnica de compreensão, interpretação e explicação, tendo por principais objetivos ultrapassar as evidências imediatas, aprofundar a percepção da realidade e verificar a pertinência, desvelando a estrutura das mensagens. A autora entende que o principal material da análise de conteúdo vem da semântica e dos significados.

${ }^{1}$ http://www.devolver.org 


\section{Resultados e discussão}

Entre os seis estudantes participantes deste estudo, três frequentam o Programa de Atendimento Educacional Especializado - PAEESP de Itaara- RS (Escola A). O programa formado por equipe de trabalho constituída, principalmente, pelas áreas da Educação Especial, Psicopedagogia, Fonoaudiologia e Psicologia, realiza um trabalho interdisciplinar de atendimento aos alunos com necessidades educacionais especiais e de assessoria pedagógica especializada junto às escolas do município.

A Escola B possui 402 alunos e destes 28 são público alvo da Educação Especial. Localiza-se na zona urbana do município - RS e atende a comunidade próxima da escola e alunos de localidades do interior do município.

$\mathrm{Na}$ escola $\mathrm{A}$ os três alunos participantes foram: A1, de 15 anos, frequentador do $9^{\circ}$ ano do ensino fundamental; A2, 13 anos, frequentador $6^{\circ}$ ano; e A3, 13 anos, frequentador $6^{\circ}$ ano. Ambos possuem deficiência intelectual e encontram-se em nível alfabético $^{2}$ no que se refere às fases de escrita.

$\mathrm{Na}$ escola B, participaram os alunos B1 tem 13 anos e frequenta o $6^{\circ}$ ano do ensino regular, este possui diagnóstico clínico de deficiência intelectual leve e encontra-se no início do nível alfabético no que que se refere a leitura e escrita. O aluno B2 tem 16 anos, frequenta o $9^{\circ}$ ano e possui diagnóstico clínico de deficiência intelectual leve e encontrase no início do nível alfabético. B3 tem 12 anos, frequenta o $6^{\circ}$ ano, é alfabetizado e apresenta indicadores de deficiência intelectual (em avaliação clínica).

A prática pedagógica, com estes seis alunos, foi realizada individualmente, durante o AEE oferecido pelos respectivos municípios a fim de evidenciar os efeitos do uso do Dvolver. Também foi necessário orientá-los sobre como construir uma história, que necessita ter uma temática e ordem cronológica, que existem diálogos e para isso, foram utilizados exemplos concretos.

Após essa orientação inicial, foram apresentadas algumas instruções básicas do funcionamento do recurso que seria utilizado (Dvolver). No atendimento seguinte foi dado início à execução da atividade de criação do vídeo com o aluno A1. Durante a realização da atividade a educadora acompanhou todo o trabalho, auxiliando o aluno e observando e registrando o andamento da tarefa, para análise posterior.

Após a finalização do vídeo respectivamente pelos alunos A1 e B1, estes eram postados no Dvolver e o link encaminhado por e-mail para a educadora da outra escola, alternando os trabalhos, para que fosse dada a continuidade da narrativa. E assim sucessivamente ocorreu com os estudantes A2, B2, A3 e B3. Desse modo, foram produzidas três histórias totalizando seis vídeos, que podem ser visualizados, por meio dos seguintes endereços: 1) O Natal Diferente ${ }^{\mathrm{i}}$; 2) $\underline{\text { Natal }^{\mathrm{ii}}}$; 3) ... iii; 4) $\underline{\mathrm{O} \text { Natal Diferente } 2^{\mathrm{iv}}}$;

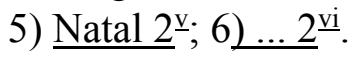

\footnotetext{
${ }^{2}$ Segundo as pesquisas de Emília Ferreiro e Ana Teberosky (1991) sobre a psicogênese da língua escrita, nível alfabético caracteriza-se pela correspondência entre fonemas e grafemas, quando o educando compreende a organização e o funcionamento da escrita e começa a perceber que cada emissão sonora (sílaba) pode ser representada, na escrita, por uma ou mais letras. Neste nível, embora já alfabetizada, a escrita ainda foneticamente (como se pronúncia), não considera as normas ortográficas da escrita padrão e da segmentação das palavras na frase.
} 
Com a utilização do software Dvolver, especificamente, apontamos que se apresenta como mais um recurso tecnológico que oferece ao educando momentos lúdicos e interativos estimulando o desenvolvimento do processo de aprendizagem. A utilização desta ferramenta durante o processo, realizou em certos aspectos a ideia de interatividade entre o aluno participante e o software, assim como entre os alunos envolvidos.

(...) um processo de troca, ação partilhada, e não apenas (...) de transmissão de mensagens; (...) um espaço que permite a participação dos interlocutores e a intervenção dos sujeitos envolvidos (...); um espaço aberto à leitura e produção crítica e analítica. (DIAS; CHAVES FILHO, 2003, p. 47)

A integração do uso de tecnologia como recurso de ensino e aprendizagem e o estímulo da criatividade e autoestima por meio da produção e publicação online de trabalho autoral foi observada como positiva em relação aos objetivos do trabalho que se propõe com os alunos envolvidos.

Dentre as observações obtidas pelas educadoras durante a aplicação da atividade e armazenadas em forma de diário de campo, salienta-se que embora alguns alunos tenham apresentado certa dificuldade em relação a criatividade para iniciar a produção, como pôde ser observado no Aluno A1, com o vídeo "O Natal Diferente", mostrou-se motivado e interessado durante todo o processo. Nesse aspecto, a atividade apresentouse desafiadora e de acordo com o interesse dos estudantes.

A partir dos aspectos observados, constata-se que softwares desse tipo estimulam a reorganização de funções cognitivas como a criatividade, atenção, imaginação, coordenação motora, memória, entre outras. Além disso, contribuem para determinar o modo de percepção e aprendizado pelo qual o sujeito conhece o objeto. Segundo Morellato (2004), alunos com necessidades educacionais especiais, interagem com o computador de forma adequada, e que o fascínio pela máquina funciona como agente motivador, por isso aprendizagem acontece informalmente e de maneira prazerosa.

Sabe-se que as TICs estão se tornando, crescentemente, importante instrumento de nossa cultura e a sua utilização um meio efetivo de interação e inclusão social. Entretanto, cabe refletir de que forma esta utilização da tecnologia é concretizada. Não significa a inserção na era da tecnologia, mas sim saber utilizar os recursos disponíveis de forma que possibilitem novas compreensões no intuito de resolver problemas do seu contexto e transformar a realidade que os cerca.

Nesse sentido, a prática desta pesquisa procurou fazer tais reflexões relacionando a utilização de uma tecnologia específica com questões de aprendizagem e interatividade. Durante a realização desta atividade, foi possível constatar que os participantes não tiveram dificuldades quanto ao acesso a ferramenta, que é disponibilizada somente online e de forma gratuita. Todos os alunos participantes já tinham familiaridade com o uso do computador e internet, em ambos os ambientes onde foi aplicada a pesquisa.

Esse resultado evidencia que mesmo sendo necessário avaliar a necessidade específica do aluno no momento da escolha do recurso, pelas múltiplas possibilidades de uso destes, a variabilidade de recursos tecnológicos atualmente disponíveis e a valorização dos potenciais dos alunos, é possível que os profissionais do AEE desenvolvam ricas experiências com o seu alunado. (CABRAL; JUNIOR, 2016, p.6)

As dificuldades apresentadas foram em utilizar o Dvolver, pois a ferramenta não 
apresentava a opção de outros idiomas, somente o inglês e a maioria dos alunos participantes desconhecia esta língua estrangeira, como no caso dos alunos B1 e B2, nas narrativas "Natal" e "O Natal diferente2". Apesar dos estudantes dominarem o uso do computador, alguns necessitaram de mediação constante para a construção de cada passo da cena.

Quanto ao aspecto da escrita foi possível constatar que os alunos conseguiram realizar as construções das frases nos diálogos sem dificuldades na utilização da ferramenta ou na exposição de suas ideias. Mas cabe ressaltar que a limitação de caracteres por diálogo (máximo 100) que o software impõe, bem como a dificuldade de utilizar a acentuação em língua portuguesa, comprometeu para alguns alunos a explanação de suas ideias, pois o texto aparecia cortado, como pode ser visto na narrativa do aluno B2, "O Natal diferente2". Acreditamos que algumas das dificuldades se deram devido ao tempo curto para trabalhar com os alunos a ideia de narrativas curtas, características da expressão em vídeo, a qual é diferente da redação de textos.

Observamos também que o software apesar de acessível (por ser gratuito e fácil de manusear), possui recursos simples e limitados, necessitando de algumas melhorias, tais como: mais opções de idiomas, possibilidade de salvar e baixar o arquivo final, mais opções de cenários e de personagens para seleção.

\section{Conclusões}

Para trabalhar com a aplicação de ferramentas interativas online com alunos com deficiência intelectual é necessário dominar o recurso que será utilizado e conhecer às características de cada sujeito que irá utilizá-lo. É importante salientar que mesmo alunos que apresentam diagnósticos similares de deficiência, poderão possuir especificidades e necessidades educacionais diferentes.

No caso desta pesquisa, o trabalho do professor necessitou de mediação entre o estudante e a tecnologia, visando tornar a atividade mais acessível. As educadoras já possuíam conhecimento de cada aluno, e puderam adaptar e acompanhar a atividade para cada um deles.

Para este trabalho observou-se que a maioria dos alunos participantes apreciaram realizar a atividade no computador. Nessa experiência demonstraram principalmente sentir-se estimulados por fazerem parte de uma criação colaborativa entre os dois municípios. Apesar de apresentarem algumas dificuldades para execução da atividade principalmente em relação ao idioma da ferramenta, que é em inglês - o aspecto da interação com outros alunos desconhecidos mas em situação similar à sua, acrescentou um aspecto lúdico a tarefa.

Assim, podemos concluir, que não existe uma metodologia única, nem em relação às tecnologias educacionais, um software específico, por exemplo, que possa abranger todas as especificidades das necessidades especiais dos estudantes. Mas é necessário que os professores aproveitem mais recursos como este no ensino-aprendizagem tanto de alunos com deficiência, como em turmas do ensino comum. Pode-se observar que softwares de produção criativa como esse propiciam aos educandos a aprendizagem de diversas habilidades, dependendo da maneira como é utilizado. 
Entendemos que este tipo de trabalho estimula o desenvolvimento de várias habilidades na aprendizagem (leitura, escrita, interpretação, criatividade) e torna o processo de aprendizagem mais significativo respeitando o ritmo de aprendizagem de cada aluno.

\section{Referências bibliográficas}

AMERICAN PSYCHIATRIC ASSOCIATION. DSM-5: manual diagnóstico e estatístico de transtornos mentais. 5. ed. Porto Alegre: Artmed, 2014.

BARDIN, L. Análise de conteúdo. 1. ed. revi. e ampli. Trad. Luís Antero Reto e Augusto Pinheiro. São Paulo: Edições 70, 2011.

BRASIL. Declaração de Salamanca e linha de ação sobre necessidades educativas especiais. Brasília: UNESCO, 1994.

BRASIL. Ministério da Educação. Grupo de Trabalho em Educação Inclusiva. Política nacional da educação especial na perspectiva da educação inclusiva. Inclusão: Revista da Educação Especial, Brasília, v.4, n.1, p.7-17, jan./jun. 2008. Disponível em: $<$ http://portal.mec.gov.br/seesp/arquivos/pdf/revinclusao5.pdf $>$. Acesso em: 05 dezembro 2016.

BRASIL. MEC. Política Nacional de Educação Especial. Brasília, DF: MEC, 1994.

BRASIL. MEC. Diretrizes Educacionais para Educação Especial na Educação

Básica. Secretaria de Educação Especial - MEC, SEESP, 2001.

CABRAL, Mozanilde Santos Nunes; JUNIOR, João Batista Bottentuit. Práticas de Ensino e Uso das Tecnologias no Atendimento Educacional Especializado: enfoque nas salas de recursos multifuncionais. Revista Renote: Novas Tecnologias na Educação. v. 14, $\quad \begin{array}{llllll}\text { n. } & 1 & \text { (2016). } & \text { Disponível } & \text { em }\end{array}$ http://seer.ufrgs.br/index.php/renote/article/view/67356> Acesso em 27 abril 2017.

DIAS, A. A. C.; CHAVES FILHO, Hélio. A gênese sócio-histórica da idéia de interação e interatividade. In: SANTOS, G. L. Tecnologias na educação e formação de professores. Brasília: Plano, 2003. p. 31-48.

FERREIRO, Emília; TEBEROSKY, Ana. Psicogênese da língua escrita. Lichtenstein, Diana Myriam (trad.); Marco, Liana Di (trad.); Corso, Mário (trad.). 4.ed. Porto Alegre: Artes Médicas, 1991.

MORELLATO, Claudete. A construção de habilidades para a resolução de problemas matemáticos em um sujeito com necessidades especiais educacionais alicerçado na informática da educação. Canoas. Universidade luterana do Brasil. (Monografia de Especialização em Informática na Educação), 2004.

MORAN, José Manuel. Novas tecnologias e mediação pedagógica. José Manuel Moran, Marcos T. Masetto, Marilda Aparecida Behrens. - Campinas, SP: Papirus, 2000. (Coleção Papirus Educação) 
SILVA, Aline Maira. Educação especial e inclusão escolar: história e fundamentos. Série Inclusão Escolar. Curitiba: Ibpex, 2010.

THIOLLENT, M.; OLIVEIRA, L. Participação, cooperação, colaboração na relação dos dispositivos de investigação com a esfera da ação sob a perspectiva da pesquisa-ação. In: CONGRESSO IBERO-AMERICANO DE INVESTIGAÇÃO QUALITATIVA, 5., Porto, Portugal. Anais eletrônicos... Disponível em $<\underline{\text { http://proceedings.ciaiq.org/2016/ }}$ index.php/ciaiq2016/issue/archive $>$ Acesso em 24 setembro 2016 . p. 357-366.

TRIPP, D. Pesquisa-ação: uma introdução metodológica. Educação e Pesquisa, São Paulo, v. 31, n. 3, p. 443-466, set./dez. 2005.

\footnotetext{
${ }^{\mathrm{i}}$ http://www.dvolver.com/live/movies-1212366

ii http://www.dvolver.com/live/movies-1215136

iii http://www.dvolver.com/live/movies-1224036

iv http://www.dvolver.com/live/movies-1218878

${ }^{v}$ http://www.dvolver.com/live/movies-1224040

vi http://www.dvolver.com/live/movies-1224567
} 